\title{
Manuscripts and letters for physica status solidi (b) - basic research and physica status solidi (a) - applied research
}

should be sent to DDR-1086 Berlin, Leipziger Straße 3-4, P. B. 1233

or

Internationaler Buchversand GmbH, 1000 Berlin' 19, Eschenallee 21.

The object of "physica status solidi (b)" and "physica status solidi (a)" is to publish rapidly important and topical results concerning fundamental research in the field of solid state physics and aspects of application and experimental techniques of fundamental solid state research, respectively. The issues of "physica status solidi (b)" and "physica status solidi (a)" will be published on the lst and the 16 th day of each month, respectively. Either series will contain the following categories:

1. Review articles written by arrangement with the editors. They will be remunerated.

2. Original papers selected from those which have not been submitted for publication elsewhere, after being reviewed. (The latest date for acceptance of contributions is the 8th and the 23rd day of each month for "physica status solidi (b)" and "physica status solidi (a)", respectively, 50 days before the delivery of the journal.)

3. Short notes published in the off-set part of the journal. They are, if necessary after being reviewed, selected by the editorial staff. (The latest date for acceptance of manuscripts for this part is the 12th and the 27th day of each month for "physica status solidi (b)" and "physica status solidi (a)", respectively, 16 days before the delivery of the journal.)

4. Pre-printed titles of papers to be published in the next issue of both series.

\section{Editorial Information}

Manuscripts should be submitted preferentially in English. Besides, papers in German, French, and Russian are admitted. The final decision on the incorporation of the papers in the series (b) or (a) is taken by the editorial staff after consultation of the referee. Authors are asked to observe the following rules:

1. Manuscripts have to be written as concisely as possible. As most, 20 and 4 pages (28 lines per page; abstracts, tables, references, figures, and captions of figures included, where 3 figures are counted as about one page) are admitted for original papers and short notes, respectively. All manuscripts should be type-written on one side only. Two copies are required. Badly arranged manuscripts are returned.

2. The author's name, initials, and institution should be given.

3. One abstract of about ten lines in English and one in German, French, or Russian are required for original papers.

4. Because of lack of space conclusions (if any) must not have the character of a summary (i.e. substantially a repetition of the contents of the abstract).

5. Formulae should not be written too small and not with pencil. Separate lines for formulae are desirable. Indistinct writing will lead to a return of the manuscript.

6. Drawings should be enclosed on separate sheets of paper, not exceeding the maximum and minimum sizes of $20 \times 30$ and $10 \times 15 \mathrm{~cm}^{2}$, respectively. Photographs should be submitted, on white paper, only for review articles and original papers. Duplicates are required.

7. Captions for the figures should be submitted on separate sheets of paper, and special instructions with regard to the size of illustrations should be given on these.

8. References should be numbered in order of appearance and should be given, on a separate sheet, in the form used in physica status solidi.

9. SI-units should be used.

10. Each paper should contain a proposal for the subject classification according to the classification scheme appearing on the second and third cover of each issue.

The authors will be sent galley proofs of review articles and original papers. Proof reading of short notes and pre-printed titles will be done by the editorial staff.

For each original paper and short note a total of 75 reprints is available free of charge. The number of reprints free of charge per review article is 25. Requests for additional reprints (against payment) should be given together with the submitted manuscripts. The deadline for orders of additional reprints is the 15th and the 30th of each month for "physica status solidi (b)" and "physica status solidi (a)" respectively, two weeks before the delivery of the journal.

All rights of reproduction, circulation, and translation are reserved by the publishers, within the legal terms of protection. 
